\title{
Challenging hypercalcaemia
}

Rahat Tauni1,2, Nida Ali1, Ritwik Banerjee $^{1}$

${ }^{1}$ Luton and Dunstable University Hospital NHS Foundation Trust, Luton, UK; ${ }^{2}$ University of Bedfordshire, Luton, UK.

\section{Clinical case}

A 43 old Asian man was referred by GP with asymptomatic hypercalcaemia of $2.87 \mathrm{mmol} / \mathrm{L}$. His past medical history included chronic plaque psoriasis with arthropathy treated with vitamin $\mathrm{D}$ analogues, hypertension treated with a thiazide diuretic, stage 3 chronic kidney disease, fatty liver with mild fibrotic change secondary to methotrexate and learning difficulties.

Biochemical investigations showed following results (Table 1 ).

\begin{tabular}{l|l}
\hline Test & Result \\
\hline Adjusted calcium & $2.78 \mathrm{mmol} / \mathrm{L}$ \\
\hline Phosphate & $0.75 \mathrm{mmol} / \mathrm{L}$ \\
\hline Magnesium & $0.76 \mathrm{mmol} / \mathrm{L}$ \\
\hline Creatinine & $146 \mathrm{micromol} / \mathrm{L}$ \\
\hline $\mathrm{PTH}$ & $1.6 \mathrm{pmol} / \mathrm{L}$ \\
\hline $25 \mathrm{OH}$ Vitamin D & $23 \mathrm{nmol} / \mathrm{L}$ \\
\hline DEXA scan & Normal bone mineral density \\
\hline Protein & $\begin{array}{l}\text { Suggestive of chronic } \\
\text { electrophresis }\end{array}$ \\
\hline
\end{tabular}

Hypercalcamia was thought to be secondary to dovonex (calcipotriene), dovobet (calcipotriol) and bendroflumethiazide as calcium was nomal prior to starting Vitamin D analogues 4 years ago. These drugs were switched to suitable alternatives and calcium levels subsequently settled to $2.62 \mathrm{mmol} / \mathrm{L}$ with $\mathrm{PTH}$ remaining normal (1.4 pmol/L).

\section{Progress}

Calcium levels stayed stable for about a year followed by an acute rise to $3.05 \mathrm{mmol} / \mathrm{L}$. Despite 3 litres of oral fluids per day, calcium further rose to $3.50 \mathrm{mmol} / \mathrm{L}$ within days and patient had to be admitted to the hospital for IV rehydration and bisphophonate. PTH was 3.1 pmol/L with mild acute kidney injury on chronic kidney disease. Repeat 24 hour urine calcium was $6.3 \mathrm{mmol}$, and CT chest, abdomen and pelvis revealed no evidence of malignancy.

Ultrasound revealed normal thyroid gland with no parathyroid adenoma(figure 1). SPECT MIBI and thyroid pertechnetate scan suggested a possibility of poorly tracer concentrated PTH adenoma (figure 2 and 3 ).

Full neck exploration identified 2 parathyroid glands (right inferior and left superior) and both were excised. Biopsy showed mild hyperplasia in both glands with no evidence of adenoma. Post operatively, calcium returned to $2.53 \mathrm{mmol} / \mathrm{L}$ with normal PTH of $1.2 \mathrm{pmol} / \mathrm{L}$.

Calcium levels remained normal for 10 months, rising to $2.67 \mathrm{mmol} / \mathrm{L}$. This was followed by recurrent severe symptomatic hypercalcaemia (calcium more than 3.4) leading to a few hospital admissions over the next few months requiring IV fluids and bisphosphonates. Other biochemistry was as follows (table 2 ).

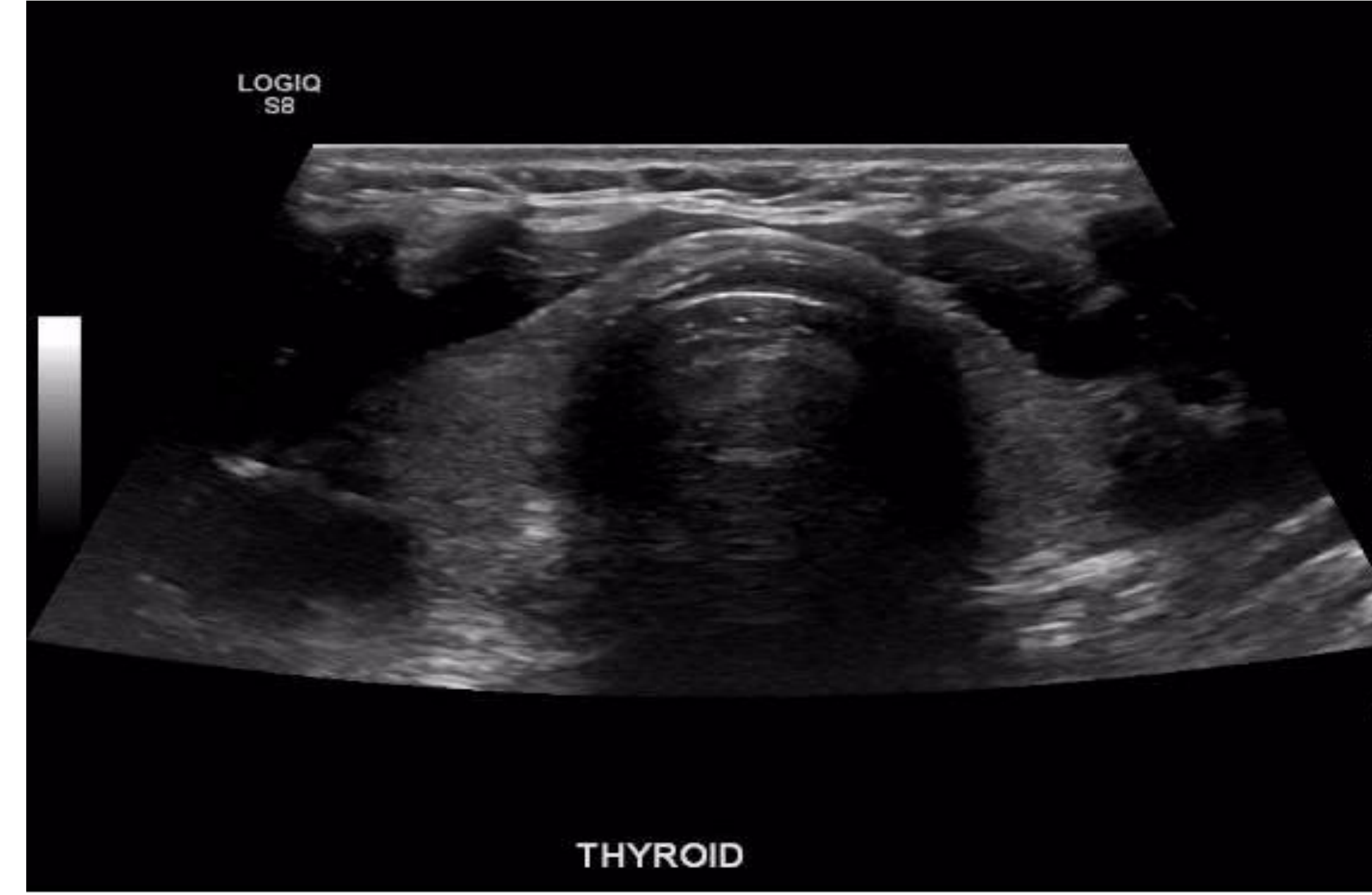

\section{Further progress}

Further parathyroid imaging did not reveal a parathyroid lesion. Parathyroid surgeon felt that a full neck exploration is unlikely to reveal a significant parathyroid lesion.

Patient continued on cinacalcet and without any further intervention, calcium levels gradually settled over months with no further fluctuations.
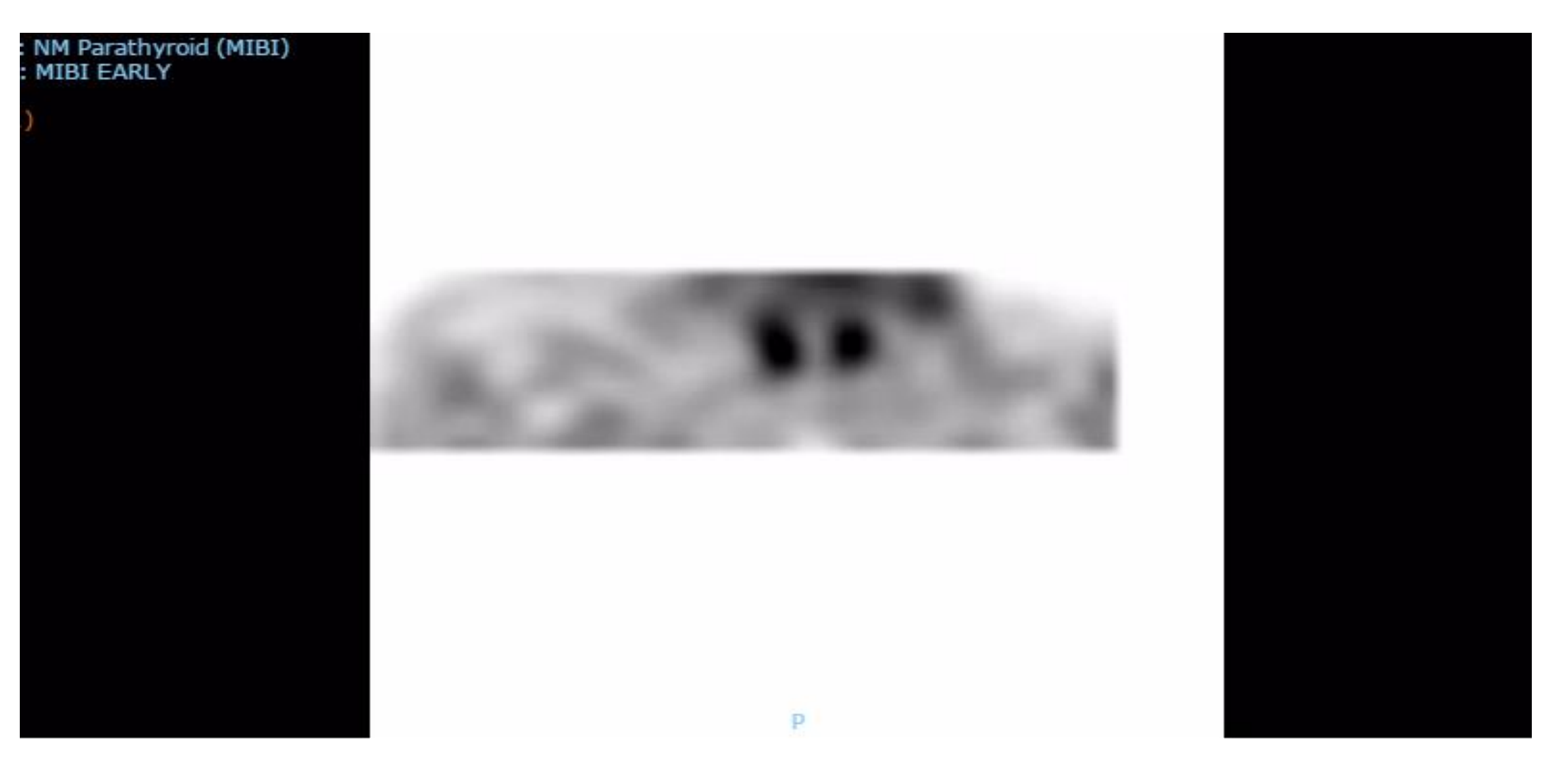

\section{Discussion}

Hypercalcaemia is one of the commonest cases seen in Endocrine clinics. It occasionally presents a diagnostic challenge, and this case is a good example where a convincing cause could not be found.

Primary hyperparathyroidism and malignancy are the commonest causes of hypercalcaemia. High or unsuppressed PTH levels usually point towards primary hyperparathyroidism. Low PTH levels should trigger further investigations especially for multiple myeloma and malignancy. Other causes include drugs (thiazides, lithium, vitamin $D$, exogenous calcium and theophylline derivatives), prolonged immobilisation, thyrotoxicosis, Addison's disease, familia hypocalciuric hypercalcaemia, sarcoidosis and granulomatous diseases.

Symptoms of hypercalcaemia are usually non specific, sometimes leading to delay in diagnosis. Severe hypercalcaemia is a medical emergency and should be managed aggressively with intravenous hydration, and other medical

Ariyan CE, Sosa JA. Assessment and management of patients with abnormal calcium. Crit Care Med. 2004

Dent DM, Miller JL, Klaff L, Barron J. The incidence and causes of hypercalcaemia. Postgrad Med J. 1987 Sep.

He was commenced on cinacalcet and a small dose of cholecalciferol with monitoring of calcium. Unfortunately, calcium and PTH levels continued to fluctuate (graph 1) without any apparent precipitating factor.

Edelson GW, Kleerekoper M. Hypercalcemic crisis. Med

Cho KC. Electrolyte \& Acid-Base Disorders. Papadakis MA, McPhee SJ, Rabow MW, eds. CURRENT Medical Diagnosis \& Treatment 2013. New York, NY: McGraw-

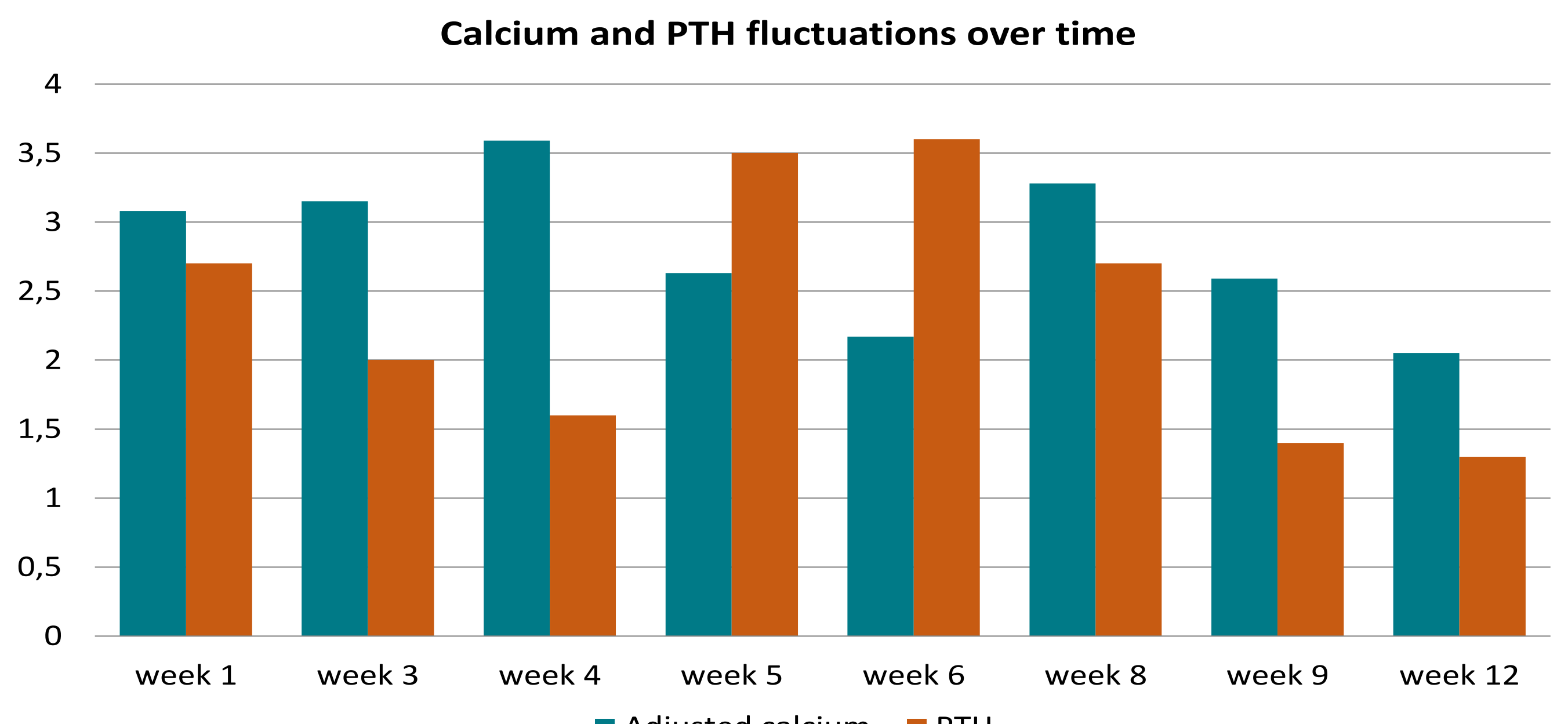
treatments if appropriate.

\section{References} Apr. 32(4 Suppl):S146-54. 63(743):745-50. Clin North Am. 1995 Jan. 79(1):79-92. Hill; 2013. Chapter 21.

Minisola S, Pepe J, Piemonte S, Cipriani C. The diagnosis and management of hypercalcaemia. BMJ.2015;350:h2723

\section{Contact}

Please contact

\begin{tabular}{|c|c|}
\hline djusted calcium & $3.4 \mathrm{mmol} / \mathrm{L}$ \\
\hline Creatinine & 209 micromol/L \\
\hline PTH & $2.6 \mathrm{pmol} / \mathrm{L}$ \\
\hline 24 hour urinary calcium & $5.3 \mathrm{mmol} / \mathrm{L}$ \\
\hline 5 OH Vitamin D & Less than $18 \mathrm{nmol} / \mathrm{L}$ \\
\hline \multicolumn{2}{|l|}{ e 2: Biochemistry results } \\
\hline \multicolumn{2}{|c|}{$\begin{array}{l}\text { was commenced on cinacalcet and a } \\
\text { nall dose of cholecalciferol with } \\
\text { onitoring of calcium. Unfortunately, } \\
\text { Icium and PTH levels continued to } \\
\text { Ictuate (graph 1) without any apparen } \\
\text { ecipitating factor. }\end{array}$} \\
\hline
\end{tabular}

rahat.tauni@yahoo.co.uk rahat.tauni@Idh.nhs.uk for any questions 